\title{
Farm-Specific Risk Analysis in Dairy Farming: A Case Study from Turkey
}

\author{
Hatice Kızılay, Handan Akcaoz*
}

Department of Agricultural Economics, Faculty of Agriculture, Akdeniz University, 07070 Antalya, Turkey \section{A R T I C L E I N F O}

Article history:

Received 22 December 2015

Accepted 25 June 2016

Available online, ISSN: 2148-127X

Keywords:

Dairy farming

Risk perception

Risk programming

Monte Carlo simulation

Antalya

${ }^{*}$ Corresponding Author:

E-mail: hvurus@akdeniz.edu.tr

\section{A B S T R A C T}

The purposes of this study were to determine the socio-economic characteristics of dairy farmers in Antalya, in Turkey, calculate the gross income, variable costs and gross margin of dairy farms, determine the probability distributions of consequences for alternative decisions to enable dairy farmers as decision makers to make a good and wellinformed choice, to determine cross effects of milk prices variations on the productive strategy of dairy farms. The data were gathered via face to face interviews in Korkuteli, Dosemealt1, Elmal1, Manavgat and Serik counties of Antalya province in Turkey. The survey study was conducted with 80 farmers, who were member of Dairy Cow Breaders Union, in the 2011 production period. In this study, on the basis of previous experience, dairy farmers assigned minimum, maximum and most likely values of milk price and yield over the next period of 5 years. Then, triangular and cumulative distributions were defined by using these values. Moreover, Monte Carlo Stochastic Simulation model was developed to obtain distribution of expected gross margin per cow. The model and triangular and cumulative distributions were built in Excel with @ Risk add-in software. The relationship of mean risk aversion coefficient, calculated by using negative exponential function, with both average gross margin and gross margin standard deviation values determined for each farm was examined. The results show that the relation between average gross margin and mean risk aversion coefficient was negative and significant at 5\% level. But, although the relation between gross margin standard deviation and mean risk aversion coefficient was found to be negative, it was not significant at $5 \%$ level.

\section{Introduction}

Dairy farming is a risky business. Typical dairy farm risks stem from the nature of the business associated with variable feed prices and milk production. Moreover, in a non-regulated dairy market, milk prices are generally rather volatile. The dairy sector is vital in Turkey since it provides traditional consumption goods. Moreover, dairy products are an important ingredient in a balanced and healthy nutrition diet. Milk production in Turkey was 18.2 million tons in 2013 of which 16.7 million tons $(91.8 \%)$ was produced by dairy cows. Furthermore, development of the dairy sector has a high priority because it generates employment and income in rural and less developed areas (TSI, 2014). According to the last Agricultural Cencus, there were 2.147 million agricultural holdings with livestock production in 2001. There were approximately 5.6 million cows in livestock farms (TSI, 2014; TSI, 2008 a,b).

In today's dynamic agricultural production systems, dairy farmers must not only excel in crop and animal production, but also be business manager, risk analyser and long-term financial planners. In addition, with narrow profit margins, dairy farmers have also been subject to extreme income variability, as a result of fluctuating yields and prices (Ceyhan et al., 2003).

The main problems of dairy industry in Turkey are supply shortage and low quality of raw milk. Small and low efficiency farms can be the reason for this problem. The production system is not oriented to meet market demand; its main objective is to ensure self-sufficiency. The low number of cattles per farm is a result of the poor quality of the farmland and the resulting low intensity of land cultivation. Considerable differences exist between the different regions and availability of irrigation has a marked influence on cattle keeping (Budak, 2009).

There are many types of risk in agriculture such as: production risk, price and market risk, institutional risk, financial risk and personal risk. It is important to understand how these risks impact upon production decisions. Different perceptions toward these risks can result in different attitudes to risk and hence different degrees of risk aversion. During the decision making process, farmers have to take account of the effects of risk. This implies that farmers allocate their investment capital and conduct their production activities to maximize the utility of their income or wealth, rather than 
to simply maximize expected profit (Zhang et al., 2010). Many researchers have conducted a lot of studies on risk attitude in dairy farming. Among them Hranaiova and Stefanoul (2002), Flaten and Lien (2005), Zhang et al. (2010), Herbst et al. (2011) have developed a model for production decision making and analysis under risks and risk preferences. Although researchers have taken risk into account in developed countries, in Turkey and in many other developing countries (Akcaoz, 2001; Akcaoz and Ozkan, 2005; Ceyhan et al., 2003; Hranaiova and Stefanou1, 2002; Marshall et al., 1997; Kizilay and Akcaoz, 2008; Uysal, 2005; Zhang et al., 2010). In Turkey, researches studies have been conducted in agriculture assuming no risk and uncertainty due to the lack of data on farm business. However, a more sophisticated understanding of risk and risk management is important for Turkish agriculture to help producers make better decisions in risky situations and to assist policy makers in assessing the effectiveness of different types of risk management tools (Ceyhan et al., 2003). Therefore the objective of this research is to determine the risk exposure of dairy farming in Turkey and to determine whether this farm-specific risk exposure is in line with the risk attitude of the dairy farmer.

The current analysis focuses on the Antalya province of Turkey. Dairy farms in the research area operate under technical, physical and socio-economic constraints and take several input-output decisions. Risk is another issue, which affects the consequences of farmer's decisions. Fluctuations in yields and prices and variations in interest payments of dairy farms lead to farm income variations and large budget deficits (Ceyhan et al., 2003). According to 2009 data, $1.2 \%$ of the total number of bovine animals in Turkey are found in Antalya province. Approximately $1.3 \%$ of the milk production takes place in Antalya (TSI, 2009). In Antalya, dairy cow breeding is an activity in around 31.000 enterprises. By the year 2009, in Antalya, $36.1 \%$ of the total numbers of dairy cows are pure breed; while $52.7 \%$ are cross breed and $11.2 \%$ are domestic breed (Anonymous, 2009).

\section{Materials and Methods}

Data in this study was collected from primary and secondary resources. The primary data was collected from dairy farmers via face to face interviews in the production year of 2010, by using a specific questionnaire. Enrolled farmers were members of the Dairy Cow Breaders Union (member farmers of the union must have more than four cows). In addition to the survey data, secondary sources such as previous research studies, production records of the Directory of Agriculture in Antalya, Dairy Cow Breaders Union and Turkish Statistical Institute were included in the study.

In this study, two major hypotheses were statistically tested to determine whether there is a relationship between Simulated Average Gross Margin and Risk Aversion Coefficient and between Standard Deviation of Simulated Gross Margin and Risk Aversion Coefficient. The two hypotheses can be specified, as follows;
Hypothesis 1: The higher the Risk Aversion Coefficient, the lower the Simulated Average Gross Margin will be.

Hypothesis 2: The higher the Risk Aversion Coefficient, the less Simulated Gross Margin Standard Deviation will be.

The primary data were collected from dairy farmers in Korkuteli, Dosemealt1, Elmalı, Manavgat and Serik counties of Antalya province. According to records of the Dairy Cows Breader Union, 89.9\% of the dairy cows in Antalya province are located in these counties. The sample size was calculated using the Neyman method (Yamane, 1967). The sample size was determined with $5 \%$ significance level and $95 \%$ confidence interval. In total, 80 farmers from these five counties were chosen for interviews using a stratified random sampling procedure. The sampling parameters are presented in Table 1.

\section{Subjective Judgements of Risks}

In decision analysis, the models should take the farmer's perception of specific risk in to account? (Ogurtsov, 2008). Risk perception is a subjective statement of risk by decision makers, their degree of belief. Risk perception is more like the mental interpretation of risk, decomposed as the chance to be exposed to content and the magnitude of the risk (Hardaker et al., 2004). Subjective judgments of farmers on both milk prices and yields have been used as a base to determine the risk exposure in dairy farming.

Farmers were informed about the historical data on milk price after displacing the effects of inflation. Farmers generally do not keep records and thus historical data on milk yield are not available in the research area. Hardaker et al. (2004) suggest that the triangular distribution is particularly useful in cases when no sample data are available and the distribution is to be assessed wholly subjectively, perhaps by a farmer (or an expert). So, the triangular distribution method has been used to obtain the marginal subjective probability distribution of milk yields for the sample farms in this study. Judgements are needed about lowest, highest and modal or most likely values of the distribution. Then, by using both price and yield probability distribution, conditional probability distribution for farm income has been obtained.

\section{Risk Attitude Elicitation and Estimation}

Like risk perception, risk attitude plays an important role in understanding the decision maker's behaviour. Risk attitude is a personal characteristic and deals with the decision-maker's interpretation of the risk and how much (s)he dislikes the outcomes resulting from the risk (Pennings et al., 2002). According to Dillon and Hardaker (1993), risk attitude is the extent to which a decision maker seeks to avoid risk (i.e. risk aversion) or prefers to face risk (i.e. risk preference). According to reasonable asset integration assumptions, a farmer would view losses or gain from specific risks as being equivalent to changes in wealth (Hardaker et al., 2004). 
Table 1 Sampling parameters of dairy producer in antalya province, Turkey, 2010

\begin{tabular}{lccc}
\hline Herd Size (cows) & Farmer Population & Farmers sampled & Distribution of Sampled farmers (\%) \\
\hline $5-9$ & 338 & 23 & 28.8 \\
$10-15$ & 102 & 29 & 36.3 \\
$16+$ & 52 & 28 & 35.0 \\
Total & 492 & 80 & 100.0 \\
\hline
\end{tabular}

*The sample size was determined with 5\% significance level and 95\% confidence interval.

\section{Reference Lottery}

In the study, reference gamble (lottery) in combination with preference scales was used to determine risk attitudes of farmers. The reference gamble is a conceptual device that has been used to aid consistent contemplation and judgement. The term preference scale is used for a numerical scale that represents an individual's preferences for a set of consequences. Higher numbers are 'more preferred' than lower numbers. IN PRESS

Preferences for alternatives with uncertain outcomes are measured by the preference scale. The general procedure is given below (Holloway, 1979). Decision makers (DM) (dairy farmers in Antalya) must make the decision between alternatives $\mathrm{A}$ and $\mathrm{B}$ and direct choice for four different value of possibility $(20,50,70$ and 90\%). If alternative $\mathrm{A}$ is chosen by the DM, increase certainty equivalent $(\mathrm{CE})$ by some amount and repeat the process. If $\mathrm{B}$ is chosen, decrease $\mathrm{CE}$ by some amount and repeat the process. Values of $\mathrm{CE}$ vary until decision makers are indifferent between alternatives $\mathrm{A}$ and $\mathrm{B}$. This value of $\mathrm{CE}$ is certainty equivalent for the uncertain event.

\section{Utility Function}

Most people are risk averse when faced with significantly risky income or wealth outcomes (Hardaker et al., 2004). A person who is risk averse is willing to forgo some expected income for a reduction in risk, the range of acceptable trade-off depending on how risk averse that individual is. This trade-off can be included by converting expected income to the utility of the individual, which means that the individuals' attitude towards risk has to be included. Conversion of income to utility is done by using a utility function (Acs et al., 2009).

Preferences vary between farmers; therefore, different assumptions can be used on their risk attitude in the range from risk neutral to extremely risk averse. The assumption of risk aversion implies a concave utility function. The utility functions need to have a mathematical form to derive risk aversion coefficients. However, there are some existing functional forms based on the properties of risk aversion. The elicited utility functions than can be tested whether it fits the existing functional form. The most commonly used functional forms are based on the constant absolute risk aversion (CARA) and constant relative risk aversion (CRRA). The one extensively used in decision analysis is the negative exponential function on the basis of CARA. CARA means that preferences among risky choices are unchanged if all out-comes are multiplied by a positive constant absolute risk aversion coefficient (Hardaker et al., 2004).
In our analysis the common negative exponential function was used. The exponential function takes the following form:

$$
\mathrm{U}=1-\exp (- \text { Ra. } \mathrm{w}) \quad \mathrm{Ra}>0, \mathrm{w}>0
$$

Where $\mathrm{U}$ is the utility of a certain person, $\mathrm{Ra}$ is the absolute risk aversion coefficient of that particular person and $w$ is the wealth measure. Concavity of this function is ensured, as $\mathrm{U}^{\prime}(\mathrm{w})>0$, and $\mathrm{U}^{\prime \prime}(\mathrm{w})<0$. This function exhibits constant absolute risk aversion. This means that preference between payoffs are unchanged if a constant amount is added to or subtracted from all payoffs (Hardaker et al. 2004).

Risk aversion coefficients $(\mathrm{Ra})$ were estimated by obtaining as a non-linear equation writing out the expected utility equation for the Lottery and the Certainty in the Excel sheet by using the above function. For this to be possible, firstly some data were entered a worksheet to be used in the equation. This data can be specified as following;

- Outcome of alternative lottery payoff

- Unmentioned outcome of alternative payoff (It was assumed that these were zero)

- Possibility values (20, 50, 70 and 90\%).

Finally, it was fiddled with risk aversion coefficients (Ra) for four possibility values until utility values gets acceptably close to zero.

\section{Risk Modelling}

Stochastic simulation which is helpful technique for analyzing risky choice is a mathematical model. Such simulation models are commonly used to analyze socalled 'what-if' questions about a real system. Such a model typically represents the relationships between the inputs and outputs of the real system and allows for the effects of chancing control or decision variables to be explored. The method is sufficiently flexible to allow the incorporation of complex relationship between variables. In stochastic simulation, selected variables or relationships incorporate random or stochastic components (by specifying probability distributions) to reflect important parts of the uncertainty in the real system (Hardaker et. al., 2004).

The producer Monte Carlo Simulation (MCS) is widely used in stochastic simulation studies for the generation of outputs given risky inputs. The risky inputs are specified by a probability distribution function. Then in a simulation (generation) of outcome values, a number 
of data points used from an input probability distribution function needs to be specified. A number of data points specifying an input distribution can also be called a number of iterations. Each iteration produces one possible outcome of system, a so-called state of nature. During a simulation, MCS randomly selects data points (values) from probability distributions (Ogurstov, 2008).

In this study, A Monte-Carlo stochastic simulation model was developed to obtain the distribution of expected gross margin per cow. The model was built in Excel with @ Risk add-in software (Palisade, 1995). MCS can be described as a method of analysis in which a computer model is created of the problem situation which can be used to determine the distributions of output variables of interest (here: gross margin per cow), given information about the stochastic input variables (here: milk production per cow, milk price, variable cost). MCS is considered to be a flexible method for investigating aspects of stochastic nature (Meuwissen et al., 2003).

In this study, three steps were used in the MCS model. First, probability distributions for milk yield and price which are risky variables - were defined, parameterized and simulated. Second, the stochastic values from the probability distributions were used to calculate gross margin variable. Third, the completed stochastic model was simulated many times (1000 iterations) using random values for the risky variables. The results of 1000 samples provided the information to estimate empirical probability distributions for the output variable (gross margin).

Simulated averages (AGM) and standard deviations (GMSD) of gross margin for each farm were calculated by applying Latin Hypercube sampling method (with 100 iterations).

Cumulative distribution function (CDF), or probability distribution function is the key to understanding Monte Carlo sampling. A cumulative distribution function $F(x)$ is a function that gives the probability $\mathrm{P}$ that the variable $\mathrm{X}$ will be less than or equal to $\mathrm{x}$, i.e.:

$$
\mathrm{F}(\mathrm{x})=\mathrm{P}(\mathrm{X} \leq \mathrm{x})
$$

Where $\mathrm{F}(\mathrm{x})$ ranges from zero to one (Hardaker et al., 2004).

A cumulative distribution function has the following properties:

1. $\mathrm{F}(\mathrm{x})$ is always non-decreasing, i.e. $\frac{d}{d x} F(x) \geq 0$

2. $\mathrm{F}(\mathrm{x})=0$ at $x=-\infty$

$\mathrm{F}(\mathrm{x})=1$ at $x=\infty$ (Vose, 2001).

\section{Results and Discussion}

The descriptive statistics of farm characteristics and variables used in the model are presented in Table 2. In the research area, total number of cows ranged from 5 to 27 heads, with an average of 9.4 cows. Moreover, on average the farms have 7.73 milking cows and 9.19 ha farm land. Gross margin (GM) is one of the most important indicators showing the success of a dairy farming. Furthermore, whether a farmer makes decision and planning for the future depends on the GM. The average GM per cow for 80 dairy farmers was 1480 TL.

\section{Risk perception}

On the basis of previous experience, the 80 dairy farmers in research area assigned minimum, maximum and most likely values of milk price and yield over the next period of 5 years. Then, triangular distribution was defined by using these values. Some statistics elicited from triangular distribution for milk yield and price are depicted in Table 3.

Table 2 Descriptive statistics of farm characteristics and the model variables for dairy farms

\begin{tabular}{|c|c|c|c|c|c|}
\hline Characteristics & Units & Mean & Std. Dev. & Minimum & Maximum \\
\hline \multicolumn{6}{|l|}{ Structural } \\
\hline Total number of cows & Units & 9.40 & 5.52 & 5.00 & 27.00 \\
\hline Number of milking cows & Units & 7.73 & 4.37 & 3.00 & 24.00 \\
\hline Total land & $\mathrm{Ha}$ & 9.19 & 7.76 & 1.20 & 43.00 \\
\hline - $\quad$ Owned land & $\mathrm{Ha}$ & 3.32 & 4.98 & 0.05 & 32.20 \\
\hline - $\quad$ Rented land & $\mathrm{Ha}$ & 5.87 & 6.68 & 0.50 & 41.80 \\
\hline \multicolumn{6}{|l|}{ Operational } \\
\hline Milk production per cow & Tonnes & 4.52 & 1.51 & 2.19 & 8.03 \\
\hline Milk price & $\mathrm{TL} / \mathrm{kg}$ & 0.70 & 0.03 & 0.62 & 0.74 \\
\hline Gross income from milk & $1000 \mathrm{TL} / \mathrm{cow}$ & 3.17 & 1.08 & 1.40 & 5.48 \\
\hline Animal sales less depr. & $1000 \mathrm{TL} / \mathrm{cow}$ & 0.89 & 0.28 & 0.45 & 1.80 \\
\hline Gross income & $1000 \mathrm{TL} / \mathrm{cow}$ & 4.06 & 1.19 & 2.27 & 7.23 \\
\hline Variable cost & $1000 \mathrm{TL} / \mathrm{cow}$ & 2.59 & 1.20 & 0.83 & 6.84 \\
\hline - $\quad$ Feed cost & $1000 \mathrm{TL} / \mathrm{cow}$ & 2.08 & 1.16 & 0.28 & 6.41 \\
\hline - Other cost & $1000 \mathrm{TL} / \mathrm{cow}$ & 0.51 & 0.19 & 0.19 & 1.00 \\
\hline Gross margin & $1000 \mathrm{TL} / \mathrm{cow}$ & 1.48 & 1.41 & -2.09 & 4.60 \\
\hline \multicolumn{6}{|l|}{ Financial variables } \\
\hline Family-farm income & 1000 TL/year & 21.63 & 3.89 & 2.76 & 38.93 \\
\hline Off-farm income & $1000 \mathrm{TL} /$ year & 15.51 & 40.87 & 3.60 & 100.00 \\
\hline Liquid capital & $1000 \mathrm{TL}$ & 15.71 & 37.80 & 0.30 & 160.00 \\
\hline Long-term loans & $1000 \mathrm{TL}$ & 15.17 & 14.30 & 1.77 & 84.00 \\
\hline \multicolumn{6}{|l|}{ Farmer specific } \\
\hline Age & Years & 48.01 & 9.77 & 25.00 & 72.00 \\
\hline
\end{tabular}


Table 3 Statistics from elicited triangular distributions

\begin{tabular}{l|cc}
\hline \multicolumn{1}{c|}{ Statistics } & Milk production per cow $(\mathrm{kg})$ & Milk Price $(\mathrm{TL} / \mathrm{kg})$ \\
\hline Minimum & 2985.81 & 0.60 \\
Maximum & 5733.33 & 1.01 \\
Mean & 4473.66 & 0.82 \\
Standard Deviation & 584.32 & 0.09 \\
5th; 95th percentiles & $3420.75 ; 5389.68$ & $0.66 ; 0.96$ \\
Coefficient of Variation & 13.06 & 10.98 \\
\hline
\end{tabular}

Table 4 Correlations Matrix of RACs

\begin{tabular}{c|cccc}
\hline Risk Aversion Coefficients & RAC(20) & RAC $(50)$ & RAC (70) & RAC $(90)$ \\
\hline RAC(20) & 1 & .209 & .067 & .043 \\
RAC(50) & & 1 & $.321(* *)$ & .204 \\
RAC(70) & & 1 & $.634(* *)$ \\
RAC(90) & & & 1 \\
\hline
\end{tabular}

**Correlation is significant at the 0.01 and 0.05 level (2-tailed).

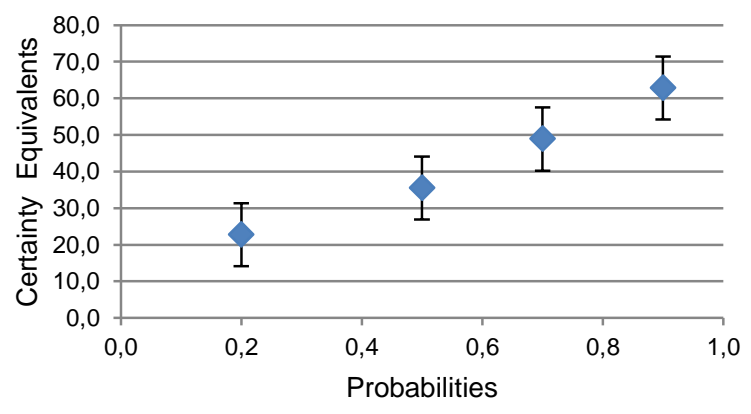

Figure 1 Relation between mean of certainty equivalents and probabilities

Table 3 shows that both milk production per cow (13.1) and milk price (11.1) were relatively variable as indicated by the coefficients of variation (CVs). But, variation in milk production per cow was higher than variation in milk price. For the period of next 5 years, milk production per cow ranged from $2985.81 \mathrm{~kg}$ to $5733.33 \mathrm{~kg}$ with a mean of $4473.66 \mathrm{~kg}$. Milk price aslo ranged from $0.60 \mathrm{TL} / \mathrm{kg}$ to $1.01 \mathrm{TL} / \mathrm{kg}$ with a mean of $0.82 \mathrm{TL} / \mathrm{kg}$. As the table shows, milk production per cow by $5 \%$ and $95 \%$ probability will be less than or equal to $3420.75 \mathrm{~kg}$ and $5389.68 \mathrm{~kg}$ respectively. Also, milk price by $5 \%$ and $95 \%$ probability will be less than or equal to $0.66 \mathrm{TL} / \mathrm{kg}$ and $0.96 \mathrm{TL} / \mathrm{kg}$ respectively.

\section{Risk Attitude}

Modes of decision making under risk bring to the forefront the fact that decisions will be affected by dairy farmers' attitudes towards risk. Consequently, it is important to quantify the dairy farmers' risk aversion coefficient. In this study, the negative exponential utility function was used to estimate absolute risk aversion coefficients of dairy farmers as decision makers. According to the results, the estimated absolute risk aversion coefficients (RAC) vary from 0.000001 to 0.000010 . The estimated RAC values vary considerably from farm to farm. Relation between mean of certainty equivalents and probabilities was presented in Figure 1.

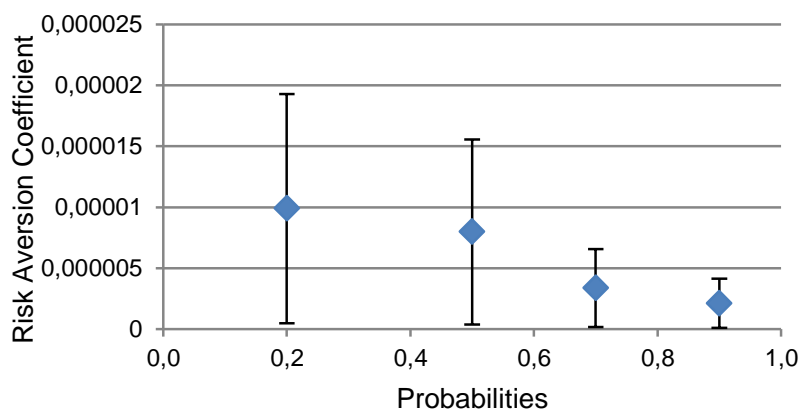

Figure 2 Relation between mean of risk aversion coefficient and probabilities

As can be seen in Figure 1, when the probabilities increase, certainty equivalents of dairy farmers also increased. The variability is about equal. While the dairy farmers are more risk averse at the point where both probabilities and certainty equivalents are the lowest, they are less risk averse at the point where both of them are the highest.

The relation between payout probabilities $(0.2,0.5$, $0.7,0.9)$ and RAC is shown in Figure 2. It can be shown that both RAC and the variability decrease with increasing probabilities. The means of certainty equivalent of each payout probability mentioned above were estimated 22.7, 35.5, 48.9 and 62.8, respectively.

The correlation coefficients between RACs (for 20, 50, 70, 90 payout probabilities) were presented in Table 4. As can be seen, RAC(70) is positively related to RAC(90) with a correlation coefficient of 0.634 which is significant at $\mathrm{p}<0.01$. Furthermore, $\mathrm{RAC}(50)$ is positively related to the $\mathrm{RAC}(70)$ (correlation coefficient is $0.321, \mathrm{p}<0.01$ ).

\section{Monte Carlo Simulation Model Results}

According to Figure 3, Gross Margin per cow was between a minimum of $341.31 \mathrm{TL}$ and a maximum of $34633.01 \mathrm{TL}$ with an expected value (or mean) of 1908.90 TL and a standard deviation around the mean of 624.11 TL. The output graph includes two delimiters. The two delimiters are markers that allow determining the 
cumulative probabilities. The leftmost delimiter is at the fifth percentile as shown by the $5 \%$ in the figure. This delimiter is at the value of $822 \mathrm{TL}$. The $90 \%$ shown in the figures indicate that there is a $90 \%$ probability that the gross margins will be greater than 822 TL but less than 2943 TL. The rightmost delimiter shows that there is a $5 \%$ probability that gross margins will be greater than or equal to 2943 TL.

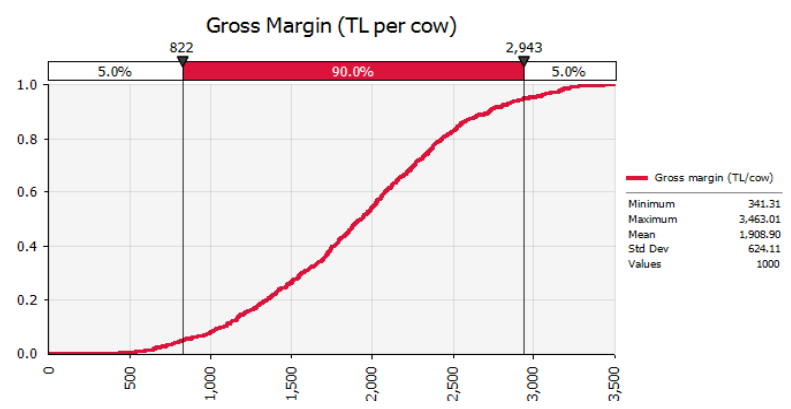

Figure $3 \mathrm{CDF}$ of gross margin per cow from @ Risk output (1000 iterations)

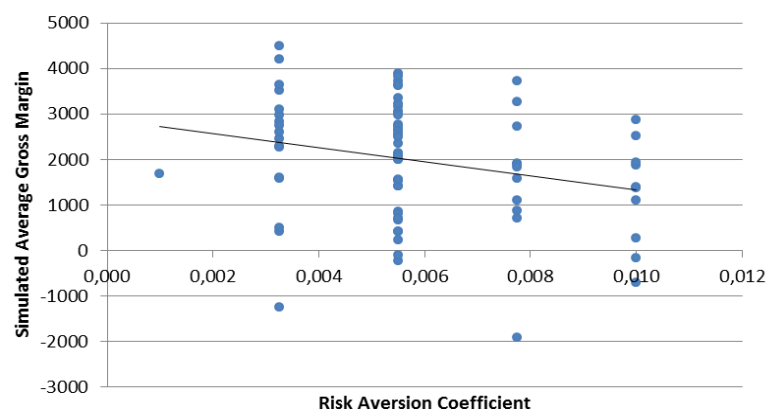

Figure 4 Relation between simulated AGM and mean of RAC

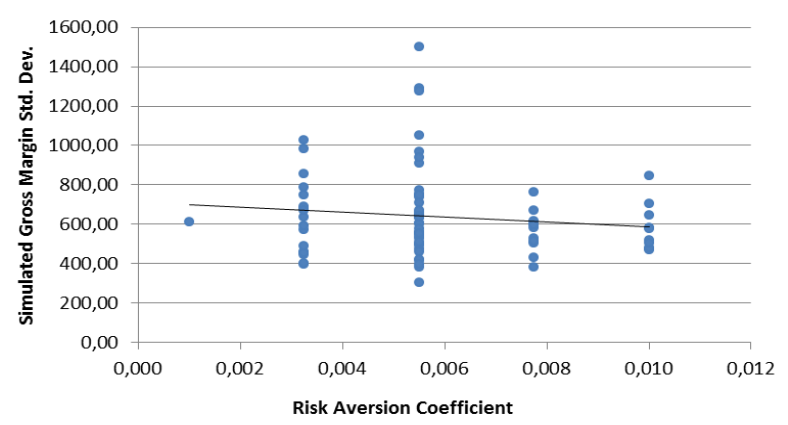

Figure 5 Relation between simulated GMSD and mean of RAC

Table 5 Results of regression analysis

\begin{tabular}{l|cccc}
\hline \multirow{2}{*}{$\begin{array}{c}\text { Risk } \\
\text { Aversion } \\
\text { Coefficient }\end{array}$} & \multicolumn{2}{|c}{$\begin{array}{c}\text { Simulated Average } \\
\text { Gross Margin }\end{array}$} & \multicolumn{2}{c}{$\begin{array}{c}\text { Simulated Gross } \\
\text { Margin Standard } \\
\text { Deviation }\end{array}$} \\
\cline { 2 - 5 } & Beta & t-value & Beta & t-value \\
\hline Means & -0.25 & $-2.26^{*}$ & -0.108 & -0.96 \\
0.20 & 0.03 & 0.218 & 0.014 & 0.126 \\
0.50 & -0.146 & -1.301 & 0.000 & 0.003 \\
0.70 & -0.252 & $-2.298^{*}$ & -0.193 & $-1.741^{* *}$ \\
0.90 & -0.216 & $-1.950^{* *}$ & -0.105 & -0.932 \\
\hline
\end{tabular}

*: Statistical significance at $5 \%$ level; **: Statistical significance at $10 \%$ level
The relationship between means of RAC with both AGM and GMSD values determined for each farm was examined. These relationships are shown in Figure 4 and Figure 5. The hypothesis were statistically tested to determine whether the relation between these values were significant. The results show that the relation between AGM and means of RAC is negative and significant at $5 \%$ level $(\mathrm{p}<0.05)$. According to the results, the hypothesis that dairy farmers with higher risk aversion had lower average gross margin (Figure 4) was not rejected. But, although the relation between GMSD and mean of RAC is negative, it is not significant at 5\% level ( $p>0.05)$. Therefore, the null hypothesis of dairy farmers with higher risk aversion had no less standard deviation of gross margin (Figure 5) was not rejected. Parameters such as $\mathrm{t}$-value and $\beta$ elicited from regression analysis are presented in Table 5.

Regression analysis was carried out to analyse separately the relationship between RAC means, 20, 50, 70 and $90 \%$ and simulated AGM and GMSD for each farm. Estimates of model are explained in Table 5. As can be seen from Table 5, while RAC (means) and RAC(70) are significant at $5 \%$ with negative effect on the simulated AGM, RAC(90) are significant at $10 \%$ with negative effect on the simulated AGM. RAC (means) is not significant at $5 \%$ with negative effect on the simulated GMSD. But, only RAC (70) is significant at $10 \%$ with negative effect on the simulated GMSD.

\section{Conclusion}

Dairy farmers make decisions in a risky environment every day. The consequences of their decisions are generally not known when the decisions are made. Furthermore, the outcome may be better or worse than expected. The variability of milk prices and yields are the most important sources of risk in dairy farming. Technology changes, legal and social concerns and the human factor itself also contribute to the risk environment for dairy farmers. The two situations that most concern the dairy farmers are: (1) is there a high probability of adverse consequences and (2) would those adverse consequences significantly disrupt the business (Kaan, 2005). The objective of this research is to determine the risk exposure of dairy farming in Turkey and to determine whether this farm-specific risk exposure is in line with the risk attitude of the dairy farmer.

In this study, two major hypotheses were statistically tested to determine whether there is a relationship between Simulated Average Gross Margin and Risk Aversion Coefficient, Simulated Gross Margin Standard Deviation and Risk Aversion Coefficient. The results show that the relation between AGM and means of RAC is negative and significant at $5 \%$ level $(\mathrm{p}<0.05)$. According to this result, it was accepted the hypothesis of dairy farmers with higher risk aversion had lower average gross margin. 


\section{Acknowledgement}

This research was supported by the Scientific Research Projects Administration Unit of Akdeniz University in Turkey.

\section{References}

Acs S, Berentsen P, Huirne R. B. M, Van Asseldonk M. 2009. Effect of yield and price risk on conversion from conventional to organic farming. The Australian Journal of Agricultural and Resource Economics 53: 393-411.

Akcaoz H. 2001. Risk in agricultural production, risk analysis and risk attitudes: applications for Cukurova Region. Department of Agricultural Economics Institute of Natural and Applied Sciences University of Cukurova. PhD Thesis, Adana, Turkey.

Akcaoz HV, Ozkan B. 2005. Determining risk sources and strategies among farmers of constrasting risk awareness: A case study for Cukurova Region of Turkey. Jornal of Arid Environment. 62: 661-675.

Anonymous 2009. Records of Antalya Directorate of Provincial Food Agriculture and Livestock, Turkey.

Budak BD. 2009. An Assessment of the competitiveness of the dairy food chain in Turkey, WP2: Studies, D'.1 Study 1: coordinator: Siemen van Berkum (LEI), February.

Ceyhan V, Bozoğlu M, Cinemre HA. 2003. Measuring yield and price risks for dairy farms and designing risk management strategies: The case of Tonya, Turkey. Die Bodenkultur 54(4): 209-214.

Dillon JL, Hardaker JB. 1993. Farm management research for small farmer development, $2^{\text {nd }}$ ed., FAO. $302 \mathrm{pp}$.

Flaten O, Lien G. 2005. Stochastic utility- efficient programming of organic dairy farms. XIth Congress of the EAAE, August 24-27, Copenhagen, Denmark.

Hardaker JB, Huirne RBM, Anderson JR, Lien G. 2004. Coping with Risk in Agriculture, $2^{\text {nd }}$ ed. CAB International, Wallingford.

Herbst BK, Anderson DP, Outlaw JL, Richardson JW. 2011. The effectiveness of dairy risk management at managing income, revenue and magrin risk. Southern Agricultural Economics Association Annual Meeting, February 5-8, Corpus Christi, Texas.

Holloway CA. 1979. Decision making under uncertainty: Models and choices. Prentice-Hall, Inc., Englewood Cliffts, New Jersey.
Hranaiova J, Stefanou SE. 2002. Scale, productivity growth and risk response under uncertainty. Economía Agraria y Recursos Naturales, 2: 73-91.

Kaan D. 2005. Defining risk and a framework for moving towards resilience in agriculture. Risk and resilience in Agriculture. Available at: http://agecon.uwyo.edu.

Kizilay H, Akcaoz H. 2008. Risk analysis of farmers that are member and non-member dairy cow-breeders union in Antalya Province. Anodolu J. Aegean Agric. Res. Inst. 18(1): 949-958.

Marshall GR, Jones RE, Wall LM. 1997. Tactical oppurtinities, risk attitude and charge of farming strategy: an application of the distribution method. The Australian Journal of Agricultural and Resource Economics. 41(4): 499-519.

Meuwissen MPM, Van Asseldonk MAPM, Huirne RBM. 2003. Alternative risk financing instruments for swine epidemics. Agricultural Systems. 75: 305-322.

Palisade 1995. @Risk-Risk Analysis and Simulation Add-in for Microsoft Excel or Lotus $12-3$. Palisade Corporation, Newfield, USA.

Pennings JME, Wansink B, Meulenberg MTG. 2002. A note on modeling consumer reactions to a crisis: the case of the mad cow disease. International Journal of research in Marketing. 19: 91-100.

Ogurtsov VA. 2008. Catastrophic risks in farm-level decision making. PhD Thesis Wageningen University, Netherlands.

TSI 2004. 2001 General Agricultural Census, Turkish Statistical Institute, Ankara, Turkey. Available at: http://www.tuik.gov.tr

TSI 2007. Statistical Yearbook of Turkey, Turkish Statistical Institute, Ankara, Turkey. Available at: http://www.tuik.gov.tr

TSI 2008a. Agricultural Statistics 1987-2006, Turkish Statistical Institute, Ankara, Turkey. Available at: http://www.tuik.gov.tr

TSI 2008b. Livestock Statistics, Turkish Statistical Institute, Ankara, Turkey. Available at: http://www.tuik.gov.tr

TSI 2009. Turkish Statistical Institute, Ankara, Turkey. Available at: http://www.tuik.gov.tr

TSI, 2014. Turkey's Statistical Yearbook, 2013. Publication Number: 4175, Ankara.

Uysal O. 2005. A Research on the attitudes of farmers towards risk: Case of Aegean Region farmers. Ege University Journal of Faculty of Agriculture. 42(3): 147-158.

Vose D. 2001. Risk analysis: a quantitative guide, John Wiley and Sons, Inc.

Yamane T. 1967. Elemantary sampling theory. Prentice-Hall Inc., Englewood Cliffs, USA.

Zhang L, McErlean S, Patton M. 2010. Impact of risk within the Northern Ireland dairy sector. The Annual Conference of the Agricultural Economics Society, Edinburgh, March, 29-31, 2010. 